\title{
Retraction Note to: Cardiac glycoside induces cell death via FasL by activating calcineurin and NF-AT, but apoptosis initially proceeds through activation of caspases
}

Pongali B. Raghavendra $\cdot$ Yashin Sreenivasan • Govindarajan T. Ramesh • Sunil K. Manna

Published online: 12 May 2013

(C) Springer Science+Business Media New York 2013

Retraction Note to: Apoptosis (2007) 12:307-318

DOI 10.1007/s10495-006-0626-3

This article has been retracted at the request of the Centre for DNA Fingerprinting and Diagnostics as it contains manipulated figures.

The online version of the original article can be found under doi:10.1007/s10495-006-0626-3.

P. B. Raghavendra · Y. Sreenivasan · S. K. Manna ( $₫)$ Laboratory of Immunology, Centre for DNA Fingerprinting \&

Diagnostics, Nacharam, Hyderabad 500076, India

e-mail:manna@cdfd.org.in

G. T. Ramesh

Department of Biology, Texas Southern University, Houston,

TX 77004, USA 